\title{
Somut Olmayan Kültürel Miras: Aşağıseyit Sudan Koyun Atlatma ve Çoban Bayramı
}

\section{Intangible Cultural Heritage: Aşagıseyit Sheep Jumping and Shepherd Dark (Sample of Shepherd's Day)}

\author{
Gülperi MEZKITT SABAN ${ }^{1}$
}

'Sorumlu yazar/Corresponding author: Gülperi Mezkit Saban (Arş. Gör. Dr.), Aksaray Üniversitesi, Fen-Edebiyat Fakültesi, Türk Dili ve Edebiyatı Bölümü, Aksaray, Türkiye. E-posta: gulperi2417@gmail.com ORCID: 0000-0001-9704-2490

Başvuru/Submitted: 10.11.2019 Revizyon Talebi/Revision Requested: 03.03.2020

Son Revizyon/Last Revision Received: 11.03.2020

Kabul/Accepted: 26.04.2020

Online Yayın/Published Online: 27.05.2020

Atıf/Citation: Mezkit Saban, Gulperi. "Somut Olmayan Kültürel Miras: Așağıseyit Sudan Koyun Atlatma ve Çoban Bayramı." Türkiyat Mecmuası-Journal of Turkology 30, 1 (2020): 181-194.

https://doi.org/10.26650/iuturkiyat.657852
ÖZ

Stoltje'ye göre eski ve gücünü çabuk toplayan kültürel form, tüm dünya toplumlarının organizasyonları ve işlevleri karşısında zengin çeşitlidir. Her ne kadar birbirlerinden farklı olsalar da festivaller, kesin karakteristik belirleyici niteliklere sahiptirler. Onlar, takvimsel düzen aralıklarıyla meydana gelir, ulusaldır, halkın iştirak ettiği kompleks bir durumdur ve tüm bunlara ses, görüntü ve amaç da eklenir. Sudan Koyun Atlatma ve Çoban Bayramı; somut olmayan kültürel miras ulusal envanterinde'Toplumsal uygulamalar, ritüeller ve şölenler' dâhilinde "Çoban Bayramları: Koç Katımı, Saya, Döl Dökümü, Yünüm-Koyun Yüzdürme" grubuna giren, gelenekleri kuşaktan kuşağa aktarma amacıyla yapılan bir kutlama olarak değerlendirilmektedir. Anadolu coğrafyasında birçok yörede bolluk ve bereket amaçlı yapılan bu ritüel, Denizli'nin Çal ilçesinde yer alan Aşağıseyit köyünde yüzyıllardır kutlanagelen bir bayram olarak bilinmektedir. Ele alınan araştırmada öncelikli amaç Aşağıseyit Köyünde yapılan Çoban Bayramı́nın geleneksel işleyişinin ve halk kültürü bağlamında işlevlerinin araştırılmasıdır. Bu çerçevede yöre halkı ile görüşmeler yapılmış ve bayram kutlamalarına dair yazılı belgeler taranmıştır. Sudan Koyun Atlatma Bayramı ve Çoban geleneğin temsilciliğini yapan çobanlar, cazgırlar ve hakem heyeti ile görüşülmüş; geleneğin himayesini yapan dönemin ağası ile de bir mülakat gerçekleştirilmiştir. Elde edilen veriler zaman, mekân ve eğlence başlıkları altında toplanmıştır. Bu çalışmada icra edilen yarışma esnasında gerçekleştirilen geleneksel halkbilimi unsurları araştııılacak, Türk kültür envanterine dâhil edilen Çoban Bayramı́nın Denizli kolu, kültürel bilginin gelecek kuşaklara aktarımı bağlamında ortaya konulacaktır.

Anahtar kelimeler: Çoban, bayram, Aşağıseyit, ritüel, koç

\section{ABSTRACT}

The cultural form, which is old and quickly accumulated, is rich in a variety of organizations and functions of all world societies. Although they are different from each other, festivals have certain characteristic determinants. They occur at intervals of calendar order, are national, a complex situation that the public participates in, and all this adds to the sound, image, and purpose. Sheep Jump and Shepherd Day from the River, in the inventory of intangible cultural heritage, it is considered a celebration that takes place in the "Shepherd Holidays: Sheep Addition, Saya, Procreation, Wool-Sheep Floating" group within the scope of 
"Social practices, rituals and feasts", to transfer the traditions from generation to generation. This ritual, which is done for the purpose of abundance and fertility in many regions of Anatolia, is known as a holiday that has been celebrated for centuries in the village of Aşağıseyit, located in the Çal district of Denizli. The primary aim of the research under consideration was to investigate the traditional functioning of the Shepherd's Feast in Aşağıseyit Village and its functions in the context of folk culture. In this regard, interviews were made with local people and written documents on the festival celebrations were scanned. Interviews were conducted with shepherds, jigglers, and an arbitral tribunal, representing tradition; An interview was also held with clergy of the period under his patronage. The data was collected under the titles of time, place, and entertainment. In this study, traditional folklore elements carried out during competition will be researched, the Denizli branch of the Shepherd's Feast, which is included in Turkish cultural inventory, will be introduced in the context of the transfer of cultural knowledge to future generations.

Keywords: Shepherd, rid, Asagisseyit, ritual, aries

\section{EXTENDED ABSTRACT}

The Shepherd's Feast; In the national breakdown of intangible cultural heritage, "Shepherds' Feast: Aries, Saya, Casting, Wool-Sheep Flotation' is considered a celebration to transfer traditions from generation to generation within the scope of 'Social practices, rituals and feasts'. Although this type of entertainment, which is generally described as Shepherd's Feast, is thought to be an eight-hundred-year tradition for the Asagiseyit Feast, it is possible to take the history to the region of Turkestan and even to the early times of mankind. This ritual, which was used for abundance and fertility in many regions of Anatolia, is known as a festival celebrated for centuries in Aşağıseyit village in the Çal district of Denizli. The primary aim of this research was to investigate the traditional functioning of the Shepherd Festival in Aşağıseyit Village and its functions in the context of folk culture. In this context, interviews were made with local people and written documents about the festive celebrations were scanned. The shepherds, jazzmen and referees who represented the tradition were interviewed; an interview was also conducted with the agha of the period under his protection. The data was collected under the titles of time, place, and entertainment. The shepherds' feast of the shepherd, which has sufficient financial background and depends on the tradition of Yoruk; It is expected that it will consist of people who make an effort to transfer the traditions. The shepherds who participate in the competition spend the day and night with the animal during the year, even sleeping in the same barn with the sheep he has choosen. It consists of people who connect with him. As the sheep follows the shepherd during the competition; it is expected to jump into the water behind the shepherd without hesitation, and that there will be a relationship based on love and obedience. The competition, which is held every year with approximately forty to fifty shepherds and herds participating, is held on the Büyük Menderes River in August. The last round of the competition is held on three stages, and the riders and shepherds remaining in the top three are chosen as the fastest crossing the Menderes River. The study analyzed the "Sheep Jumping and Shepherd Festival" under the title of traditional entertainment, social rituals, festivities and festivals, within the national inventory of "Shepherd's Feast: Sheep Addition, Saya, Cum Cast, Wool-Sheep Floating". This ritual, which can be included in practices related 
to nature and the universe, is important in the context of preserving the continuity of the cultural heritage of society, as it is a live practice on the basis of keeping traditional folklore products alive and transferred to future generations. In this study, traditional folklore elements performed during the competition were investigated and the Denizli branch of the Shepherds' Feast included in the Turkish culture inventory was put forward in the context of the transfer of cultural knowledge to future generations. "The Convention on the Protection of Intangible Cultural Heritage, which was accepted by UNESCO in 2003 and entered into force in 2006, is to ensure that the traditional knowledge and cultures that humanity has created in hundreds or even thousands of years and transmitted from generation to generation in oral cultural environments will be be transferred to future generations". Intangible cultural heritage is the common memory of the society that created and preserved this heritage, and then of all humanity. This shared memory has emerged in historical continuity as a shared experience, and this knowledge will be needed in the future. It is a historical responsibility to protect this cultural heritage and to teach it to future generations. 


\section{Giriş}

Somut olmayan kültürel miras; "toplulukların, grupların ve kimi durumlarda bireylerin, kültürel miraslarının bir parçası olarak tanımladıkları uygulamalar, temsiller, anlatımlar, bilgiler, beceriler ve bunlara ilişkin araçlar, gereçler ve kültürel mekânlar olarak ifade edilmektedir." 17 Ekim 2003 tarihinde toplanan UNESCO’nun Genel Kurulu'nda alınan kararlar neticesinde Somut Olmayan Kültürel Miras, beş madde ile çerçevelenmiştir. Sözlü gelenekler, gösteri sanatları, toplumsal ritüeller, şenlikler ve festivaller, doğa ve evren ile ilgili uygulamalar ve son olarak da el sanatları geleneği, somut olmayan kültürel halkbilgisi uygulamalarının formunu oluşturmaktadır. ${ }^{2}$ Araştırma ele alınan "Sudan Koyun Atlatma ve Çoban Bayramı" adlı geleneksel eğlence, toplumsal ritüeller, şenlikler ve festivaller başlığı altında, Kültür Bakanlığı'nın oluşturduğu, “Çoban Bayramları: Koç Katımı, Saya, Döl Dökümü, YünümKoyun Yüzdürme" ulusal envanteri dâhilinde incelenecektir. Aynı zamanda doğa ve evren ile ilgili uygulamalara da dahil edilebilecek olan bu ritüel, geleneksel halkbilgisi ürünlerinin yaşatılması ve kuşaklara aktarımı zemininde canlı bir uygulama olduğu için toplumun kültürel mirasının devamlılığının korunması bağlamında da önemi haizdir. Oğuz Öcal'ın deyimiyle somut olmayan kültürel miras, "bu mirası yaratan ve koruyan toplumun sonra da bütün insanlığın ortak belleğidir. Bu ortak bellek, paylaşılan bir deneyim olarak tarihsel süreklilik içinde ortaya çıkmıştır ve bu birikime insanlığın gelecekte de gereksinimi olacaktır. Bu kültürel mirasın korunması ve gelecek kuşaklara öğretilmesi tarihsel bir sorumluluktur."’3

Sudan Koyun Atlatma ve Çoban Bayramı, her ne kadar Türk eğlence kültürü tarihinde Türkistan coğrafyasında yaşanan tarihi dönemlere kadar götürebilirse de; esasen tarihin bilinen ilk dönemlerine kadar götürmek de mümkün olabilecektir; çünkü “İnsanoğlu, ilk dönemlerden itibaren doğadaki değişimleri gözlemiş; bu değişimleri açıklamak ve kendi lehine çevirmek için çabalamıştır. Doğadaki değişimlerin zararlı etkilerinden korunmak, yağmur yağdırmak, güneşi çıkarmak, hayvanların üremesini sağlamak, bolluk ve bereketi arttırmak için içerisinde bazı işlemlerin de yer aldığı törenler düzenlemiştir." ${ }^{2}$ Özellikle hayvanların kuzulama, kırpılma zamanlarında yahut mevsimsel düzenin bozulduğu zamanlarda icra edilen törenler, bir çeşit dua ayini özelliği gösterse de aynı zamanda halkın küçükten büyüğe geleneklerini icra ettiği ve bu suretle geleneklerin aktarım zemini olarak görülen mekân özelliği taşıma bakımından da kayda değerdir.

Eski Türk düşüncesinde yaratıcı güç olarak kabul edilen Gök-Tanrı'dan başka çeşitli olağanüstü güçlerin varlığına inanılıyor ve bunlar için birtakım törenler düzenleniyordu. Ayrıca yılın değişmesiyle ilgili astronomik olaylar ve ekolojik gelişmeler, tarım ve hayvancılıkla

1 Öcal Oğuz, Somut Olmayan Kültürel Miras (SOKÜM) İhtisas Komitesi, SOKÜM Nedir? (Ankara: Gelenekel Yayınc1lık, 2013b) 5.

2 Metin Ekici vd. Somut Olmayan Kültürel Miras: Barana (Dursunbey-Balıkesir), (İzmir: Uşşak Tif Ofset Matbaacılık, 2011).

3 Öcal Oğuz, Somut Olmayan Kültürel Miras Nedir? (Ankara: Geleneksel Yayıncılık, 2013a), 65-73.

4 Kültür ve Turizm Bakanlığı Kolektif. Somut Olmayan Kültürel Mirasın Korunması Temel Belgeler (Ankara: Başak Matbaacılık, 2011), 8 . 
ilgili bazı özel günler, birtakım kutlamalara zemin hazırlıyordu. Türklerin Orta Asya'dan getirdikleri bu inanç ve yaşam biçimiyle yerleşik düzende edinilen yeni alışkanlıklar, bu tören ve şenliklerin daha belirginleşmesini sağlamış ve insanımızın bir takvim geleneği kazanmasını zorunlu kılmıştı. Böylece Anadolu' da yüzyıllar boyunca devam edecek bir gelenek oluşmuş, bu törenlerin dramatik ögeleri ise oyun kültürünün gelişmesini hızlandırmıştı. Belirli günlerde oynanan oyunlar da bu yolla bolluk, bereket sembolü haline gelmişti. ${ }^{5}$ Temelde mevsimlik bayram olan ve sonradan sudan koyun atlatma bayramı olarak adlandırılan ve takvimsel olarak Koç Katımı ritüeli olarak bilinen bu gelenek, Anadolu coğrafyasında Denizli dışında; Kars'ta, Malatya'da, Rize'de, Ağrı'da, Erzincan'da, Van'da, Şanlıurfa'da, Osmaniye'de, Iğdır'da, Uşak'ta, Burdur'da, Antalya'da, Mersin'de, Konya'da, Karaman'da, Nevşehir'de, Yozgat'ta, Kayseri'de, Sivas'ta, Mardin'de ve Adıyaman'da da aynı tarihlerde izlenmektedir.

Boratav mevsimlik bayramlardan olan çoban bayramını, genel mevsimlik bayramlar gurubuna dâhil eder. Çoban bayramı zinciri olarak nitelediği bu gurupta Koç Katımı, Saya ve Döl başlıkları altında toplar. Boratav’ın verdiği bilgiye göre hemen her yerde düzenlenen törenlerde ilk güne çok özel bir önem verilir. O gün davul zurnalarla köy halkı köy meydanında toplanır. Çobanlar süslenmiş, kınalanmış koçları dişi koyunlara salarlar. ${ }^{6}$ Koç katımını asıl amacı koyunların yavrulama zamanlarını kontrol altına alma ve sürünün devamlılığını sağlamadır. Koç katımı sayesinde kışın doğacak koyunlar hem açlıktan hem de sert hava şartlarından korunmuş olmaktadır. ${ }^{7}$

2003 yılında UNESCO tarafından kabul edilen ve 2006 yılında yürürlüğe giren Somut Olmayan Kültürel Mirasın Korunması Sözleşmesi, insanlığın yüzlerce hatta binlerce yılda yarattığ1 ve sözlü kültür ortamlarında kuşaktan kuşağa aktardığı geleneksel bilgilerin ve kültürlerin korunmasını ve gelecek kuşaklara aktarılmasını sağlamaktır. ${ }^{8}$ Temelinde bolluk bereket ve soyun devamlılığını sağlamak olan bu eğlencenin asıl amacı aynı zamanda yöre insanın kültürel hafızasını oluşturan Yörük kültürünü, eğlencenin icra edildiği ortamda paylaşmak ve gelecek kuşaklara aktarmaktır.

\section{Sudan Koyun Atlatma ve Çoban Bayramı'nın İşlevleri}

Eski ve gücünü çabuk toplayan kültürel form, tüm dünya toplumlarının organizasyonları ve işlevleri karşısında zengin çeşitlidir. Her ne kadar birbirlerinden farklı olsalar da festivaller, kesin karakteristik belirleyici niteliklere sahiptirler. Onlar, takvimsel düzen aralıklarıyla meydana gelir, ulusaldır, halkın iştirak ettiği kompleks bir durumdur ve tüm bunlara ses, görüntü ve amaç da eklenir. ${ }^{9}$ Başta Çal halkı olmak üzere Denizli’nin hemen her ilçesinden

5 Dilaver Düzgün, “Geleneksel Türk Tiyatrosu”, Türkler, 15 (Ankara: Yeni Türkiye Yayınları, 2002), 322.

6 P. Naili Boratav, 100 Soruda Türk Halkbilimi, (Ankara: Bilgesu Yayıncılık, 2013), 241.

7 O. Güner Şimşek, İ. “Iğdır'da Halk Takvimi ve Halk Meteorolojisi”, Türk Coğrafya Dergisi, 33 (1998)134.

8 Öcal Oğuz, "Sunuş", Somut Olmayan Kültürel Mirasın Geleceği Türkiye Deneyimi, (Ankara: Grafiker Yayınları, 2013b.), 137.

9 Stolotje Beverly J. "Festival”, Milli Folklor, çev. Petek Ersoy. 67 (Ankara 2005), 160. 
ve hatta Ege Bölgesi'nde yaşayan çobanların iştirak ettiği, Sudan Koyun Atlatma ve Çoban Bayramı, 'Koç Katımı' zamanı olarak da bilinen ve yörede ağustos sonu- eylül başına denk gelen zamanda yapılmaktadır. Çoban maharetinin vurgulandığı, çoban ile koyun arasındaki sıkı bağın sonucunda gerçekleştiğine inanılan efsaneye dayanarak; Türk boylarının yaklaşık sekiz yüz yıl önce ilk defa Denizli-Çal coğrafyasına yerleşme tarihi esas alarak o dönemden itibaren yaşatıldığı düşünülen geleneğin, Yörük kültürünü koruyarak nesilden nesile aktarma ve sosyal yaşama dair değerleri yaşatma işlevi olduğu düşünülmektedir. Bascom'un ortaya koyduğu halkbilgisi ürünlerinin işlevlerinden olan eğlendirme ve eğitme işlevi bu bağlamda değerlendirilmektedir.

a. Aktarım İşlevi: Nebi Özdemir'in ${ }^{10}$ de sıklıkla vurguladığı gibi festival, şenlik ve bayramlardaki damıtılmış ve kalıplaşmış haldeki unsurlar, aynı zamanda geleneksel belleğin ve bilginin aktarılması işlevine de sahiptir. Diğer bir ifadeyle bu tür sosyokültürel olaylar, toplumsal düzenlerin ve siyasal sistemlerin varlığını ve sürekliliğini temin eden "emniyet sübapları"dır. Kabul edilmiş davranış örüntülerini sürdürme işlemi olarak adlandırılan ve folklorun işlevlerinden biri olarak düşünülen 'kültürü aktarma ve sürdürme', Sudan Koyun Atlatma ve Çoban Bayramı'nda, yarışma öncesinde okunan maniler ve dualarla, yarışma esnasında giyilen kıyafetler ve sergilenen ritüelistik hareketlerle, yarışma sonrasında verilen yemekler ve sergilenen yöresel oyunlarla gerçekleşmektedir. Stoltje’nin de belirttiği üzere festivaller, kolektif bir olağanüstülüktür ve grup hayatında kökleşmiş amaçlara hizmet eder. Prestij ve üretimin dağıtımına bağlı olarak paylaşılan sorumluluk, katılımın devamlılığını kesinleştirir. Çal yöresinin kolektif olarak sahiplendiği ve kendilerinde 'Yörük kültürünü yaşama ve yaşatmayı' görev addetmeleri, Stoltje'nin vurguladığı kökleşmiş amaçlara ve paylaşılan sorumluluğa işaret etmektedir. Aynı zamanda yarışmayı izlemeye gelen seyirciler arasında gelişen sohbet esnasında gerçekleşen sosyal etkileşim de yörenin kültürü olan Yörük kültürünün kuşaklararası aktarımına vesile olmaktadır.

b. Eğlendirme İşlevi: Folklorun önde gelen işlevi olarak düşünülen eğlenme ve eğlendirme işlevi bağlamında değerlendirilen Sudan Koyun Atlatma ve Çoban Bayramı'na, Türkiye'nin hemen her bölgesinden meraklıların gelip düzenlenen ritüele katılması, katılımcılara hoş vakit geçirtirken; izledikleri yarışma da izleyicilerin eğlenmesini sağlamış ve bu suretle kişilerin 'yaşadıkları an'ı da keyifli geçirmelerine ve hayattan zevk almalarına da aracılık etmektedir.

\subsection{Zaman}

Denizli-Çal yöresinde, 26-28 Ağustos’ta, 847 yıldır yapıldığı iddia edilen ve koyunların koç katımı dönemine denk gelen yapılan bayram kutlamasının ilk günü, kuzu güzellik yarışması, köpek güzellik yarışması, koyun kırpma yarışması ve en anaç koyun yarışması yapılmaktadır. İkinci gün ise sudan koyun atlatma yarışması düzenlenmektedir. Kaynak kişinin deyimiyle

10 Nebi Özdemir, Türk Eğlence Kültürü, (Ankara: Akçağ Yayınevi, 2005), 50. 
"kendisini Türk hisseden herkesin davetli olduğu" gelmesinden ötürü her ne kadar katılım yoğun olsa da; yaz döneminin en sıcak zamanına rastlamasından dolayı belli bir yaşın üzerindeki kimselerin gelmekte zorlandığı belirtilmektedir.

\subsection{Mekân}

Her y1l geleneksel olarak 26-28 Ağustos'ta yapılan Sudan Koyun Atlatma ve Çoban Bayramı, Denizli ilinin Çal ilçesine bağlı olan Aşağıseyit Mahallesi'nden geçen Büyük Menderes Nehri'nin üzerinde yapılmaktadır. Burada belirtilmesi gereken husus, nehrin görece daha sığg; çoban ve koçları için büyük risk oluşturmayacak derinlikte bir alan seçilmesidir.

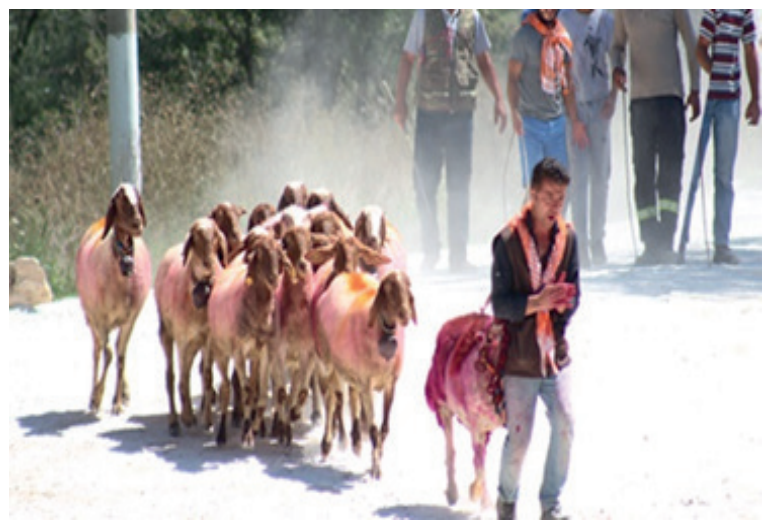

Resim 1. Çoban, elci koç ve sürüsü ile Büyük Menderes Nehri'ne atlarken

\subsection{Eğlence}

\section{a) Hazırlık}

Çobanlar koyunlarıyla, samimiyet, sevgi ve güvene dayalı bir ilişki kurmak için neredeyse yirmi dört saat koyunuyla birlikte vakit geçirmekte ve hatta geceleri de ahırda uyumaktadır. Kaynak kişinin deyimiyle "elci koyununla ahırda uyumazsan mümkün değil kazanamazsın."12 Bir diğer kaynak kişinin aktarımına göre, çobanlar suya birlikte atlayacağı hayvanla aynı ahırda uyumasının yanı sıra çoban koyununa elini koyar da yatar. ${ }^{13}$ Bu yarışlara katılacak olan çobanlar el koyunlarını bir yıl öncesinden ya da daha kuzu iken seçmeye başlarlar ve bu doğrultuda eğitim vererek beslerler. El koyunu olacak nitelikleri taşıyan kuzu çobanın peşinden hiç ayrılmaz, sürekli onunla birlikte hareket eder. Bu özellikteki kuzuları el koyunu olarak yetiştiren çobanlar ise bunların satışından da güzel bir gelir elde ederler. ${ }^{14}$

11 Kaynak Kişi 1: Fethi Akçam, yüksekokul mezunu, Çal, 48.

12 Kaynak Kişi 2: Suat Bektaş, ilkokul mezunu, Baklan-Çataloba, 42.

13 Kaynak Kişi 6: Arif Lahnacı, ilkokul mezunu, Çal- Yukarıseyit, 32.

14 O. Ayşegül Koyuncu, “Asırlık Bir Sevda Öyküsü: ‘Aşağıseyit Köyü Sudan Koyun Atlatma Yarışı ve Yörük Şenliği”. Turkish Studies, 10/14 (Sonbahar 2015), 483-508. 


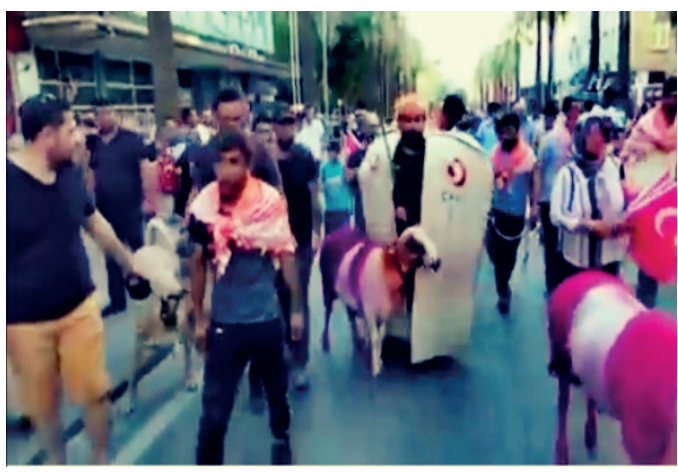

Resim 2. Denizli meydanında kortej yürüyüşü

Sudan Koyun Atlatma ve Çoban Bayramı'na katılmak isteyen her çoban, Çal ilçesinde bulunan ilçe tarım müdürlüğüne kaydını yaptırmaktadır. Koyun sürüleri yarışma gününden bir gece evvel yola çıkmaktadır. Başlarında çobanlarıyla birlikte durarak, dinlenerek ve zaman zaman uyuyarak da koyunlar güdüle güdüle yarışmanın yapılacağı alana gelmektedir. ${ }^{15}$ Öncelikle şehir merkezinde, 26 Ağustos sabahı, Valilikten belediyenin önüne kadar 1,5 kilometrelik mesafede kortej yürüyüşü yapılır. Bu yürüyüşe çoban köpekleri ve çobanların yarıştıracakları koyunları da yanlarında olur. Kortejin amacı, Denizli halkını bayram kutlamalarına davet etmektir. Bu yürüyüş esnasında çobanlar, yörenin yerel oyunu olan harmandalı zeybeğini davul zurna eşliğinde sergileyerek yoluna devam eder. Islıklar ve düdük sesleriyle ilerleyen kortejin ellerinde Türk bayrakları ve davet pankartları taşırlar. Belediyenin önüne gelen kortej bir dakikalık saygı duruşunun ardından İstiklal Marşı’nı okur ve yürüyüş sona erer. Ertesi gün sabah 9:00'da etkinlikler koyun kırpma yarışması ile başlar. Aynı gün en güzel çoban köpeği yarışması da yapılır. Akşam, yerel sanatçıların verdiği konserlerle halk, bayram meydanına çekilir. İkinci gün ise yörede bulunan türbelerin ziyaretinin ardından sudan koyun atlatma yarışması yapılır.

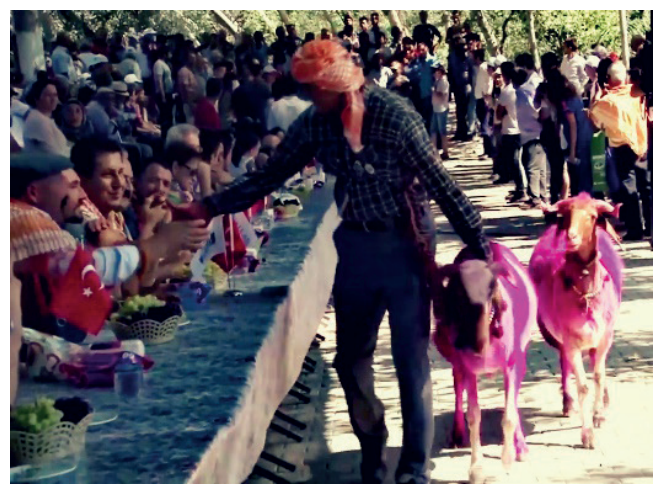

Resim 3. Jüri önünden çoban ve sürüsü geçerken...

15 Kaynak Kişi 6: Arif Lahnacı, ilkokul mezunu, Çal- Yukarıseyit, 32. 


\section{b) Oyun}

Türk halk eğlencelerinin kurallarının niteliği ve niceliği, eğlencenin hangi kültür ortamında yaratıldığı ve icra edildiğiyle yakından ilgilidir. Birinci sözlü kültür ortamında kurallar, toplumsal bellekte yaşatılır ve gelenek ya da adet adı altında, sözlü/sözsüz ortaya konur. Geleneksel eğlence dünyasının birinci sözlü ortamındaki kuralları Özdemir' in ${ }^{16}$ ifadesiyle genellikle kısa, özdür ve sayıca azdır. Bir dakikalık saygı duruşu ve İstiklal Marşı'nın ardından yapılan protokol konuşmalarının sonrasında Menderes Nehri üzerinde kurulan yere gelinmektedir. Genellikle veterinerlerden oluşan hakem heyeti, koyunların önlerinden geçecekleri ve koyunları genel itibariyle inceleyebilmek üzere belirlenen yerlerine oturmaktadır. Çoban ile birlikte yarışacak asıl koyuna ‘elci koyun' denilmektedir. Çobanlar da sürüleriyle birlikte sıra haline gelip koşmayı beklerler. Her sene yaklaşık 40-50 arasında değişen yarışmacı içerisinden, jüri üyeleri ilk etapta fiziken iyi görünen ve hızlı koşan koyunları seçer. Bu yürüyüşün adına Çoban Kortej yürüyüşü denmektedir. Ardından ikinci tur başlar. İkinci turda, suya çobanının ardından en hızlı girenler seçilip son tura kalır. Son tura genellikle dört ya da beş tane çobanıyla birlikte koyun kalır. Son kalan dört beş kişi içinden koyunuyla en uyumlu ve suya en hızlı giren ve karşıya en hızlı geçen koyun ve çobanı birinci seçilir.

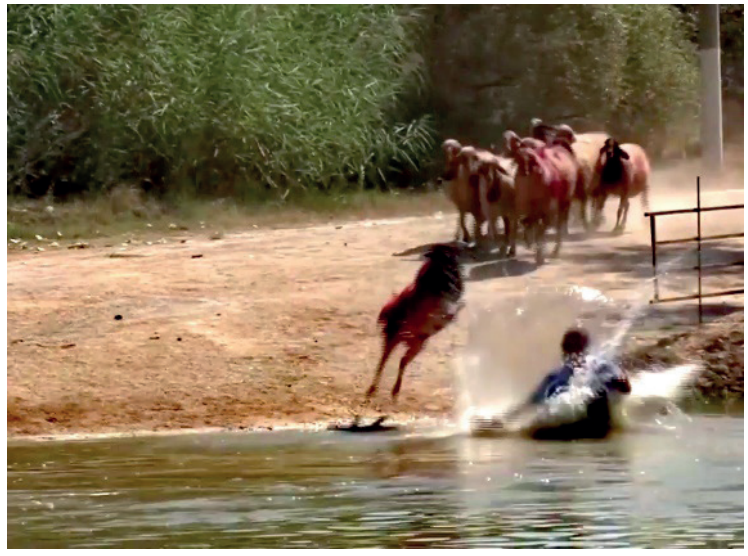

Resim 4. Yarışma esnasında çobanın hemen ardından elci koç atlarken

\section{c) Oyun Ödülleri}

Koyunu suya en hızlı atlayan çoban, göğsünü kabartarak kahvede oturur. Koyunu suya atlamayan çoban da boynunu bükerek oturur. Bir çeşit güç ve maharet gösterisi olarak da görülür. Kim kazandıysa bugün en az altı yedi ay gönlü ruhu şen olur. Çobanlar için bundan başka bir eğlence yok. Yıl boyu tüm hazırlıklar bugün için yapılır. ${ }^{17}$ Çobanların derdi günü bu gündür. Birinci olana kupanın yanı sıra destekleyici firmalar yem ve efsanede çobanların koyunlara

16 Nebi Özdemir, Türk Eğlence Kültürü (Ankara: Akçağ Yayınevi, 2005), 121.

17 Kaynak Kişi 2: Suat Bektaş, ilkokul mezunu, Baklan-Çataloba, 42. 
yedirdiği tuzu temsilen tuz hediye edilmektedir. Bazen de ilk gelene altın ve çobanına özel yapım kepenek hediye edilmektedir. Katılımcılarla yapılan görüşmelerde, amacın maddi gelir etmek değil geleneği devam ettirmek olduğu söylenmektedir. ${ }^{18}$ Festivallerin diğer önemli amaçları ise atayı anmak, ataya ibadet etmek, yüksek değerdeki hüner ve yeteneklerin performansı veya grup miraslarının eklemlenmesine bağlı olarak gerçekleştirilen grup benzerliğinin ifadesidir. ${ }^{19}$ Katılımcıların, aynı zamanda, birçoğunun kendisini ‘öz Yörük’ olarak tanımlamakta ve her biri kendisini vatan sevgisi ve kültürlerine olan düşkünlükleri ile tanımlamakta, bayram kutlamalarına katılım amaçlarının da bu birliği sağlamak olduğunu ileri sürmektedirler.

\section{d) Efsane}

Horasan'dan, Hoca Ahmed Yesevi'nin gönderdiği dervişlerinden gelenlerin bu bölgeye yerleştiğini ve Yörük geleneğinin de onlar aracılığıyla yöreye geldiğine inanan halk, Sudan Koyun Atlatma ritüeline yörede yaşandığına inanılan bir Yörük efsanesiyle kutsallık ve tarihi derinlik kazandırır. Efsaneye göre, yörede yaşayan çoban ile Bey’in kızı birbirini sevmektedir. Çoban öylesine âşıktır ki köylünün hayvanlarını gütmeyi bırakır. Hâl böyle olunca köylüler toplanır ve Bey'in makamına gelir. Allah'ın emri ile Bey'den kızını isterler; ancak hakir gördüğü çobana kızını vermek istemeyen Bey, çobanın ısrarları üzerine çobandan yapması çok mümkün olmayacak bir iş ister. Bu iş de Ağustos sıcağında koyunlarına tuz yedirmesi, üç gün boyunca su vermemesi ve bu haldeyken koyunlarını Büyük Menderes'in üzerinden su içmeden ve hayvanları boğulmadan karşıya geçirmesidir. Çoban da bu şartları koyununa anlatır. Koyun da çobanın aşkını bilmektedir. Verilen görevi yapabileceğini söyleyen çoban, tuzu koyunlarına yedirir ve haydi ak koyun, kara koyun, mor koyun diyerek bağırır. Kara koyun tüm koyunların önüne çıkar ve arkasından bütün koyunlar gelir. Çoban, istenilen şekilde koyunları su içirmeden karşıya geçirir. Çobanın verilen görevi başarı ile tamamlamasına karşın, Bey yine de kızını çobana vermez. Bu olay üzerine Bey’in kızı aşkından hasta olur yataklara düşer ve ölür. Kızının ölümüne çok üzülen ve öfkelenen Bey de çobanı köyden kovar. Köyden kovulan çoban da kendini dağlara atar ve kaval çalarak ömrünü tamamlar.

\section{e) Yöresel Maniler ve Halk Oyunları}

Eğlence mekânları, aynı zamanda Türk kültürünün yaratıldığı, icra edildiği ve değiştirildiği; çoğunlukla geleneksel, sözel bilginin aktarıldığı ve yerel yaşantının canlı tutulduğu, özetle geleneği egemen olduğu belli başl1 "kamusal alanlar"dır. ${ }^{20}$ Yörede bilinen Çoban Efsanesi'nin yanı sıra, kültürel ve edebi veriler üretmeye devam eden bu ritüelin en bilinen manisini, her sene bayram kutlamasına gelip yarışmaya katılan Çal'ın hemen yan ilçesi olan Baklan ilçesi Çataloba Köyü'nden gelen Ahmet Karaduman şöyle dile getirir:

18 Kaynak Kişi 5: Yaşar Celal Ceylan, üniversite mezunu, Denizli, 51.

19 Stolotje Beverly J, "Festival” Milli Folklor. Çev. Petek Ersoy. 67, (Ankara 2005), 160.

20 Nebi Özdemir, Türk Eğlence Kültürü (Ankara: Akçağ Yayınevi, 2005), 114. 
Her tarlayı motorla sürmezler.

Her kızı sevdiğine vermezler.

Aşağıseyit hak etmeyince,

Bu başı da kimseye vermezler

Motorlar çıkmış arkası sabansız olmaz.

Her mesleğin başı, çobansız olmaz.

Aşağıseyit'te koyun yarışları olmayınca;

Çal tarafının da yakışığı olmaz.

Tren istasyonlarında olmuş katar,

Ağalar oturmuş masaya cigaranın iyisini atar.

Bu gördüğünüz el koyunu suyu görünce;

Vallahi çobanı üzerinden atar.

Şaşkın, tarlalara fi mi ekilir?

Yağmurlar yağınca kökü mü sökülür?

Yabandan gelen gelinin kahrı mı çekilir?

Büyük sulara heves çekende güzel koyun çekilir.

Düz ovalarda bu ekinleri biçerim.

Yârimin kınalı ellerinden zehir de içerim.

Böyle nehirlerde değil;

Köprüden bile olsa atlar geçerim.

Bir diğer mani örneği:

Tarlanın taşlısı,

Kızın gardaşlısı,

Çobanın sarı başlısı,

Koyunun mor başlisı.

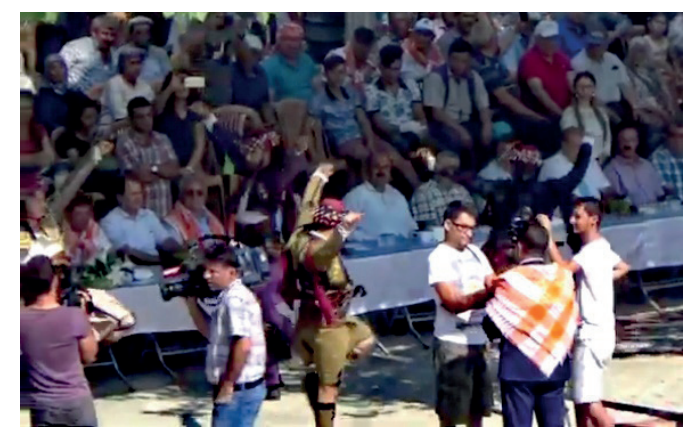

Resim 5. Yöresel halk oyunlarından Zeybek oynayanlar

Yörenin bilinen çalgısı sipsi ile müzisyenler bu düzenlemeye katılmakta ve yerel ezgileri icra etmektedirler. Sipsinin yanı sıra davul ve zurna eşliğinde gelen müzisyenleri de görmek mümkün olabilmektedir. Zeybek havaları eşliğinde oynanan oyunlar, bayram yerinin hemen her yerinde sergilenmektedir. 


\section{f) Giyim Kuşam ve Süslenme (Hayvan Süslemesi ve Çoban Kıyafetleri)}

Koyunların düğünü çobanların bayrami ${ }^{21}$ olarak ifade edilen bu kutlama alanına gelen koyunlar da sergilenmek üzere çeşitli süsleme materyalleriyle donatılmaktadır. Koyunlar, genel olarak pembe, sarı ve mor renge boyanmakta; başları oyalarla ve nazar boncukları ile süslenmektedir. Yünleri kırpılarak şekil verilen koyunların boyunlarına ve başlarına ay yıldızlı takılar takılmaktadır. Aynı şekilde çoban kepenekleri de ay yıldızla ve nazar boncukları ile süslenmektedir. Bayram kutlamalarına katılan kişiler de Yörük atkısı adı verilen turuncu-beyaz atkıları sırtlarına bağlayıp gelmektedir.

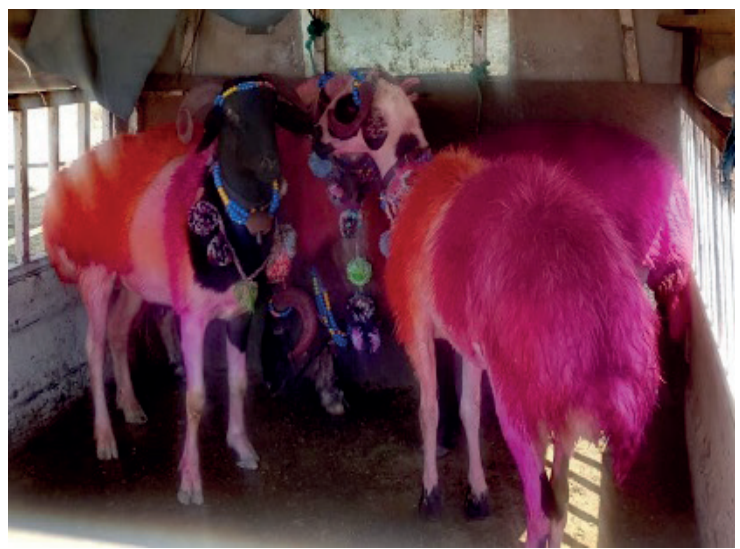

Resim 6. Yarışacak elci koyunların süslenmiş hali

\section{g) Ağalık sistemi}

Mesleki veya parasal gücün etkisiyle eğlence düzenleyerek, içinde bulunulan toplumda statü kazanma yöntemine (alınan statü), diğer ülkelerde olduğu gibi Türkiye'de de sıklıkla rastlanmaktadır. ${ }^{22}$ Düzenleyen kişiye saygınlık ve ün kazandıran bu eğlencelerde Bayram kutlamalarına, yörede yaşayan ve durumu iyi olan kimseler maddi finansmanı sağlamak üzere 'ağa' olarak seçilmektedir. 2019 yılında yapılan görüşmelerde, son on beş yıldır ise 'Zekiye Çelebi’ adında bir kadın ağanın, düzenlemenin maddi finansmanını sağladığı belirtilmektedir. Zekiye Çelebi ile yapılan görüşmede, kendisinin Yörük olduğunu ve bu düzenleme ile Yörük kültürünün sürekliliğinin sağlandığını, kendisinin de en çok bu sebeple maddi destek sağladığını anlatmıştır. Bayram yerine ellerini kınalayarak gelen Çelebi, yöresel kıyafetiyle birlikte alanda bulunup, görüşmeye gelen gazeteciler ve medya temsilcileriyle röportaj yapmakta ve bu ritüeli neden desteklediğini açıklamaktadır.

21 Kaynak Kişi 4: Ramazan Mercan, ortaokul, Dinar, 53.

22 Nebi Özdemir, Türk Eğlence Kültürü (Ankara: Akçağ Yayınevi, 2005), 142. 


\section{Sonuç}

Kökeninde bolluk, bereket uygulamaları gibi ritüel pratikler bulunan Sudan Koyun Atlatma ve Çoban Bayramı'nın, verimsizliğin ve kıtlığın yerini bolluk berekete bırakılması amaçlanarak yüzyıllardır gerçekleştirildiğine inanılmaktadır. Geleneği icra edenler bağlamında bu ritüelin iki önemli sebebi vardır. Birincisi, Yörük kültüründe yer alan hayvan sevgisini ispat etmektir. Bu bağlamda İspanya'daki boğa güreşlerinde, hayvanlara yapılan eziyetin aksine çobanların koyunlarına olan sevgisi neticesinde oyunun kazanıldığını ve ilaveten yöredeki koyun yetiştiricilerin, civar köylerde hiç su görmemiş koyunların dahi, çobanlarıyla kurduğu ilişki ve samimiyet sayesinde sudan atlayıp yüzerek karşıya geçebildiklerini belirtmektedir. Çobanlar; hayvanın etini, sütünü, derisini ve yününü vermesine karşılık olarak çobanın da ona saygı ve sevgisini gösterdiğini, hayvan sahiplerinin, hayvanlarına tutku ile bağlı olduklarını, ihtiyaç dolayısıyla koyunlarını bırakıp yöre dışına çıktıklarında dahi bir an önce koyunlarının yanına dönmek istediklerini, koyunlarıyla adeta aşk yaşadıklarını belirtmektedir. Bu sebeple İspanya'daki Boğa Güreşlerine rakip olduklarını iddia etmektedirler. Yöre insanının bu ritüeli icra etmesindeki ikinci neden de Yörük kültürünü yaşamak, yeni gelen nesillere aktarmaktır. Aynı zamanda Yörük kültürünü tanıtmak için de bir firsat olarak görülmektedir. Dondurarak değil aktararak yani yaşatarak bir koruma amaçlanmaktadır ki bu da somut olmayan kültürel mirasın kuşaklar arasında aktarımı ile mümkün olacaktır. Takvimsel bayramlara dâhil edilecek olan ve Yörük şenliği olarak da adlandırılan düzenlemedeki amaç aynı zamanda Yörük birliği ve beraberliğini sağlamaktır.

Son yıllarda medyanın da ilgisini çeken bayram kutlamalarına, ulusal kanalların birçoğu haber bültenlerinde yer vermektedir. Ortak bellekte paylaşılan bir deneyimin ürünü olan şölene iki yüzün üzerinde fotoğraf sanatçısının katıldığı belirtilmektedir. Somut olmayan kültürel miras, bu mirası yaratan ve koruyan toplumun sonra da bütün insanlığın ortak belleğidir. $\mathrm{Bu}$ ortak bellek, paylaşılan bir deneyim olarak tarihsel süreklilik içinde ortaya çıkıı̧tır ve bu birikime insanlığın gelecekte de gereksinimi olacaktır. Bu kültürel mirasın korunması ve gelecek kuşaklara öğretilmesi tarihsel bir sorumluluktur.

Hakem Değerlendirmesi: Dış bağımsız.

Çıkar Çatışması: Yazar çıkar çatışması bildirmemiştir.

Finansal Destek: Yazar bu çalışma için finansal destek almadığını beyan etmiştir.

Peer-review: Externally peer-reviewed.

Conflict of Interest: The author has no conflict of interest to declare.

Grant Support: The author declared that this study has received no financial support. 


\section{Kaynaklar/References}

Boratav P. Naili. 100 Soruda Türk Halkbilimi. Ankara: Bilgesu Yayıncılık, 2013.

Düzgün, Dilaver. "Geleneksel Türk Tiyatrosu”, Türkler. 15 Ankara: Yeni Türkiye Yayınları, 2002.

Oğuz, Öcal. Somut Olmayan Kültürel Miras Nedir? Ankara: Geleneksel Yayınc1lık, 2013a.

Oğuz, Öcal. Sunuş. Somut Olmayan Kültürel Mirasın Geleceği Türkiye Deneyimi. Ankara: Grafiker Yayınları, $2013 b$.

Ekici, Metin vd. Somut Olmayan Kültürel Miras: Barana (Dursunbey-Balıkesir). İzmir: Uşşak Tif Ofset Matbaac1lik, 2011.

Koyuncu O. Ayşegül. "Asırlık Bir Sevda Öyküsü: Aşağıseyit Köyü Sudan Koyun Atlatma Yarışı ve Yörük Şenliğì”. Turkish Studies. 10/14 (Sonbahar 2015): 483-508.

Kültür ve Turizm Bakanlı̆̆ı Kolektif. Somut Olmayan Kültürel Mirasın Korunması Temel Belgeler. Ankara: Başak Matbaacıl1k, 2011.

Özdemir, Nebi. Türk Eğlence Kültürü. Ankara: Akçağ Yayınevi, 2005.

Stolotje Beverly J. "Festival”. Milli Folklor. Çeviren Petek Ersoy. 17 ( 2005): 60-65.

Şimşek, O., Güner, İ. “Iğdır'da Halk Takvimi ve Halk Meteorolojisi”, Türk Coğrafya Dergisi. 33 (1998): 129-135.

Turan, Fatma Ahsen. “Orta Asya'dan Anadolu'ya Mitik Yolculukta Tabiat Olayları”, Milli Folklor. 90 (2011): 49-60.

\section{Kaynak Kişiler}

Kaynak Kişi 1: Fethi Akçam, üniversite Yüksekokul, Çal, 48.

Kaynak Kişi 2: Suat Bektaş, ilkokul, Baklan-Çataloba, 42.

Kaynak Kişi 3: Ahmet Karaduman, lise, Baklan-Çataloba, 29.

Kaynak Kişi 4: Ramazan Mercan, ortaokul, Dinar, 53.

Kaynak Kişi 5: Yaşar Celal Ceylan, üniversite, Denizli, 51.

Kaynak Kişi 6: Arif Lahnacı, ilkokul, Çal- Yukarıseyit, 32.

Makalede kullanılan resimler, Gülperi Mezkit Saban'ın arşivindendir. Arşivleme çalışması 2017-2018 2019 yıllarında gerçekleştirilen Sudan Koyun Atlatma ve Çoban Bayramı esnasında yapılmıştır. 